\title{
Mediating effects of social and personal religiosity on the psychological well being of widowed elderly people.
}

\begin{abstract}
Spousal death is one the most stressful life events that seriously affects the psychological well being of widowed. This study examined the mediating effects of social and personal religiosity on the psychological well being of widowed elderly people. The sample for this study was comprised of 1367 widowed and married elderly Muslims from Malaysia. Psychological well being, religiosity, and physical health were measured using WHO-5 Well being Index, Intrinsic Extrinsic religiosity scale, and a checklist of 16 physical health problems, respectively. Data analysis was conducted using the Statistical Package for Social Sciences (version-13). As expected, bivariate correlation analysis revealed that widowhood is statistically and negatively associated with psychological well being. Results of multiple hierarchical regression analyses and Sobel test showed that only the indirect effect of widowhood through personal religiosity was statistically significant (Sobel $=-2.79, \mathrm{p}<.01$ ). Sobel test for social religiosity was not significant (Sobel $=-1.54, \mathrm{p}>.05)$. The results of this study confirmed earlier studies, which found that widowhood negatively affects psychological well being of elderly people. Overall, the findings show that the potential solace provided by religiosity can decrease the negative effects of widowhood on the psychological well being of widowed elderly people.
\end{abstract}

Keyword: Death; Elderly; Malaysia. 